\title{
Risk factors of chest wall invasion in non-small cell lung cancer
}

\author{
Nozomu Motono ${ }^{1}$, Shun Iwai ${ }^{1}$, Aika Yamagata ${ }^{1}$, Yoshihito Iijima ${ }^{1}$, Katsuo Usuda ${ }^{1}$, Sohsuke Yamada $^{2}$, \\ Hidetaka Uramoto ${ }^{1}$
}

${ }^{1}$ Department of Thoracic Surgery, Kanazawa Medical University, Uchinada, Ishikawa, Japan; ${ }^{2}$ Department of Pathology and Laboratory Medicine, Kanazawa Medical University, Uchinada, Ishikawa, Japan

Contributions: (I) Conception and design: N Motono; (II) Administrative support: N Motono; (III) Provision of study materials or patients: N Motono; (IV) Collection and assembly of data: N Motono, S Iwai, A Yamagata, Y Iijima, K Usuda, S Yamada; (V) Data analysis and interpretation: N Motono, H Uramoto; (VI) Manuscript writing: All authors; (VII) Final approval of manuscript: All authors.

Correspondence to: Nozomu Motono, MD, PhD. Department of Thoracic Surgery, Kanazawa Medical University, 1-1 Daigaku, Uchinada, Ishikawa 920-0293, Japan. Email: motono@kanazawa-med.ac.jp.

Background: The risk factors for the development of chest wall invasion (CWI) in non-small cell lung cancer (NSCLC) patients are unclear. If the risk factors for the development of CWI can be clarified, surgical treatment might be able to be performed before CWI development, thus improving the prognosis.

Methods: In the present study, we enrolled patients who received surgery for NSCLC between January 2008 and December 2019 with available data on the maximum standardized uptake value $\left(\mathrm{SUV}_{\max }\right)$ on positron emission tomography (PET) with lesions adjacent to the visceral pleura. Furthermore, the preoperative white blood cell (WBC) count, the preoperative neutrophil-to-lymphocyte ratio (NLR), platelet (Plt) count, levels of lactate dehydrogenase $(\mathrm{LDH})$ and C-reactive protein $(\mathrm{CRP})$ were analyzed as predictive factors of CWI.

Results: The relationships between CWI and clinicopathological variables were analyzed, and there were significant differences between patients with and without $C W I$ in the age $(\mathrm{P}=0.02)$, maximum tumor diameter on computed tomography $(\mathrm{CT})(\mathrm{P}<0.01)$, diameter of tumors adjacent to the visceral pleura $\left(\mathrm{P}_{\max }\right)$ $(\mathrm{P}<0.01), \mathrm{SUV}_{\max }(\mathrm{P}<0.01)$, maximum tumor diameter on a pathological examination $(\mathrm{P}<0.01)$, WBC count $(\mathrm{P}=0.03)$, Plt count $(\mathrm{P}=0.04)$, and levels of $\mathrm{LDH}(\mathrm{P}<0.01)$ and $\mathrm{CRP}(\mathrm{P}=0.01)$. Logistic regression analyses of the risk factors related to CWI showed that the age $(\mathrm{P}=0.02), \mathrm{P}_{\max }(\mathrm{P}=0.02), \mathrm{SUV}_{\max }(\mathrm{P}=0.01)$, and LDH $(\mathrm{P}<0.01)$ were significant risk factors.

Conclusions: The age, $\mathrm{P}_{\max }, \mathrm{SUV}_{\max }$, and LDH levels might be associated with CWI.

Keywords: Chest wall invasion (CWI); non-small cell lung cancer (NSCLC); risk factor

Submitted Apr 21, 2020. Accepted for publication Sep 23, 2020.

doi: $10.21037 /$ jtd-20-1722

View this article at: http://dx.doi.org/10.21037/jtd-20-1722

\section{Introduction}

Lung cancer with chest wall invasion (CWI) is reported to account for $3 \%$ to $8 \%$ of all resected non-small cell lung cancer (NSCLC) cases (1-4). The first surgical treatment for lung cancer with CWI was described in 1947 (5), and since then, resection for NSCLC with CWI has been considered an option for multidisciplinary therapy to improve the prognosis (3,4,6-9).

CWI is categorized as T3 stage in the tumor, nodal and metastatic (TNM) staging system, $8^{\text {th }}$ edition, of the American Joint Committee on Cancer (AJCC)/Union for International Cancer Control (UICC) for NSCLC, and the 5 -year survival rate of NSCLC patients with T3NOM0 is reported to be $52 \%$ (10). Furthermore, the depth of CWI has been reported to potentially worsen the prognosis $(3,8,11)$, performing resection before CWI occurs is ideal. Although CWI can be diagnosed by imaging tools, such as computed tomography (CT), magnetic resonance image (MRI), and ultrasound (12-15), the risk factors for the 


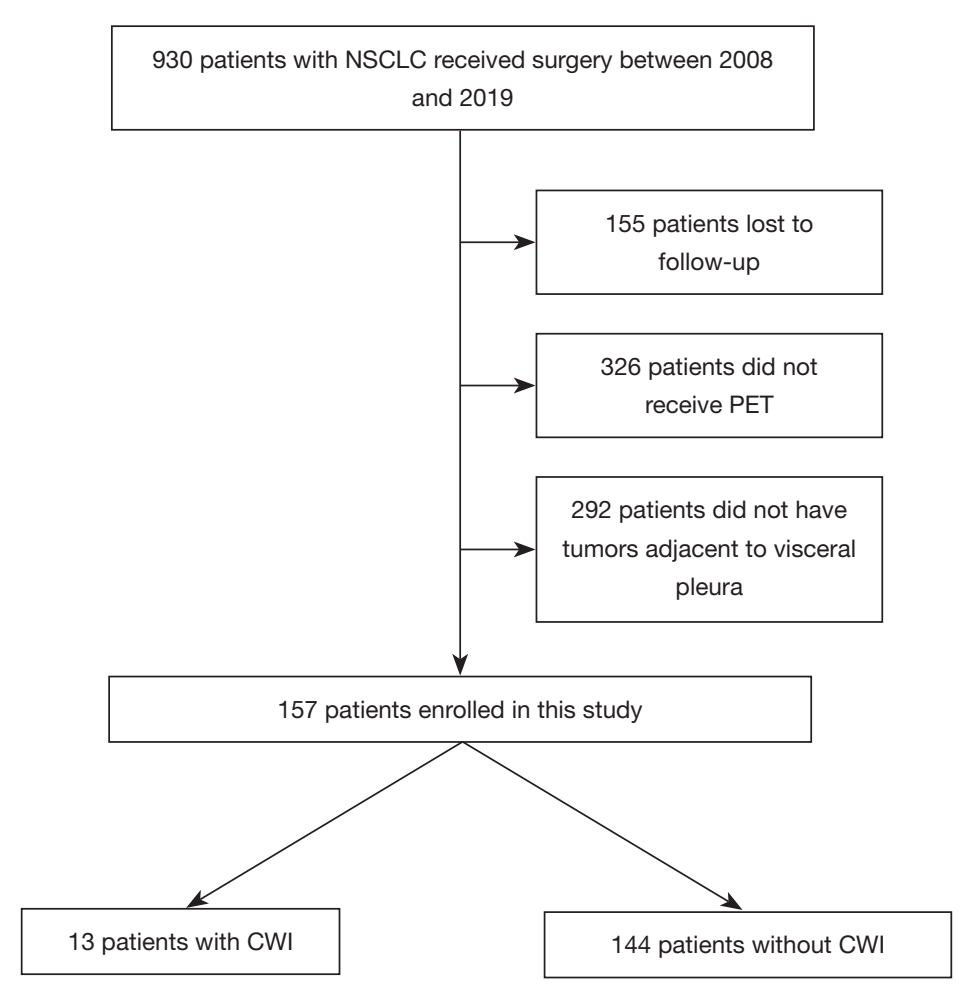

Figure 1 Flowchart for patient enrollment. NSCLC, non-small cell lung cancer; CWI, chest wall invasion; PET, positron emission tomography.

development of CWI in NSCLC patients are unclear. If these risk factors could be clarified, surgical treatment might be able to be performed before CWI development, thus improving the prognosis.

In the present study, we retrospectively analyzed the relationship between clinicopathological factors and CWI in NSCLC patients and examined whether or not it was possible to assess the risk of CWI.

We present the following article in accordance with the STROBE reporting checklist (available at http://dx.doi. org/10.21037/jtd-20-1722).

\section{Methods}

\section{Patients}

Nine hundred and thirty NSCLC patients who underwent surgery at Kanazawa Medical University between January 2008 and December 2019 were identified. Among these, 155 patients were lost to follow-up, 326 did not undergo positron emission tomography (PET), and 292 did not have a lesion adjacent to the visceral pleura. Therefore, 157 patients were enrolled in the present retrospective study (Figure 1). The lifetime cigarette consumption was assessed using the Brinkman index, which is calculated as the number of cigarettes smoked per day multiplied by the number of years for which the subject has smoked.

\section{Tumor diameter}

The maximum tumor diameter and diameter of tumors adjacent to the visceral pleura were measured on chest CT. The maximum tumor diameter on CT was defined as the $\mathrm{CT}_{\max }$, and the diameter of tumors adjacent to the visceral pleura was defined as the $\mathrm{P}_{\max }$. The maximum tumor diameter on a pathological examination was defined as the $\mathrm{Patho}_{\max }$.

\section{Maximum standardized uptake value ( $S U V_{\text {max. }}$ )}

${ }^{18} \mathrm{~F}$-fluoro-2-deoxy-glucose $\left({ }^{18} \mathrm{~F}\right.$-FDG)-PET was performed with a dedicated PET camera (SIEMENS Biograph Sensation 16; SIEMENS, Erlangen Germany) before surgery. All patients fasted for $6 \mathrm{~h}$ before undergoing scanning. The dose of ${ }^{18} \mathrm{~F}-\mathrm{FDG}$ administered was $3.7 \mathrm{MBq} / \mathrm{kg}$ of the patient's body weight. After a 60 -min uptake period, an emission scan was acquired for 3 min per bed position, and a whole-body scan was performed according to the 
height of each patient. After image reconstruction, a twodimensional (2D) round region of interest (ROI) was drawn on a slice after visual detection of the highest count on the fused CT image. For lesions with negative or faintly positive PET findings, the ROI was drawn on the fusion image obtained with the corresponding CT image. From those ROIs, the $\mathrm{SUV}_{\max }$ was calculated.

\section{Blood chemistry test}

The preoperative white blood cell (WBC) count, platelet (Plt) count, and levels of lactate dehydrogenase (LDH) and $\mathrm{C}$-reactive protein (CRP) were analyzed as predictive factors of CWI. Furthermore, the preoperative neutrophilto-lymphocyte ratio (NLR) was analyzed as well.

\section{Clinical and pathological diagnoses}

Clinical and pathological TNM staging was performed in all patients based on the $8^{\text {th }}$ edition of the AJCC/UICC classification.

\section{Statistical analyses}

Pearson's chi-square test for independence was used to compare frequencies of clinicopathologic variables. The cut-off values for the clinicopathological factors related to CWI were calculated according to a receiver operating characteristics (ROC) curve analysis. The predictive factors related to CWI were analyzed by a logistic regression analysis. All statistical analyses were two-sided, and statistical significance was defined as a $\mathrm{P}$ value of less than 0.05 . The statistical analyses were conducted using the JMP software program (Version 13.2; SAS Institute Inc., Cary, NC, USA).

\section{Ethical statement}

The study was conducted in accordance with the Declaration of Helsinki (as revised in 2013). The institutional review boards of Kanazawa Medical University approved the protocol (the approval number: I392), and written informed consent was obtained from all patients.

\section{Results}

\section{Patients' characteristics}

The relationship between CWI and the clinicopathologic characteristics of these 157 patients is shown in Table 1 . The median age of patients with CWI was significantly younger than that of the patients without CWI (65 vs. 68 years, $\mathrm{P}=0.04)$. The median values of $\mathrm{CT}_{\max }$ (63 vs. $40 \mathrm{~mm}, \mathrm{P}<0.01), \mathrm{P}_{\max }(75$ vs. $29 \mathrm{~mm}, \mathrm{P}<0.01)$, and $\mathrm{Path}_{\text {omax }}$ (65 vs. $42 \mathrm{~mm}, \mathrm{P}<0.01$ ) of patients with CWI were significantly larger than those of patients without CWI. The median SUV ${ }_{\max }$ of patients with CWI was significantly higher than that of patients without CWI (18.8 vs. 9.4, $\mathrm{P}<0.01)$. The median levels of LDH (238 vs. $193 \mathrm{U} / \mathrm{L}$, $\mathrm{P}<0.01)$ and CRP (0.6 vs. $0.19 \mathrm{mg} / \mathrm{dL}, \mathrm{P}=0.01)$ of patients with CWI were higher than those of patients without CWI.

\section{Relationship between CWI and clinicopathological variables divided by an ROC curve analysis}

The cut-off value for the clinicopathological variables related to pleural dissemination was calculated by an ROC curve analysis, and the relationships between CWI and the clinicopathological variables of NSCLC patients are shown in Table 2. There were significant differences in the age $(\mathrm{P}=0.02), \mathrm{CT}_{\max }(\mathrm{P}<0.01), \mathrm{P}_{\max }(\mathrm{P}<0.01), \mathrm{SUV}_{\max }(\mathrm{P}<0.01)$, Patho $_{\max }(\mathrm{P}<0.01)$, WBC count $(\mathrm{P}=0.03)$, Plt count $(\mathrm{P}=0.04)$, levels of $\mathrm{LDH}(\mathrm{P}<0.01)$ and $\mathrm{CRP}(\mathrm{P}=0.01)$ between CWI group and non-CWI group.

\section{Logistic regression analyses}

The results of logistic regression analyses of the risk factors related to CWI are summarized in Table 3. The age $(\mathrm{P}=0.02)$, $\mathrm{P}_{\text {max }}(\mathrm{P}=0.02), \mathrm{SUV}_{\max }(\mathrm{P}=0.01)$, and LDH level $(\mathrm{P}<0.01)$ were identified as significant risk factors related to $\mathrm{CWI}$.

\section{Discussion}

Surgical treatment for NSCLC patients with CWI has not been considered as contraindication from the last twodecades, and the prognostic improvement has been reported (1-4,6-9). Several prognostic factors for NSCLC patients with CWI were reported. The completeness of resection and involvement of lymph nodes were mainly considered prognostic factors, whereas the depth of CWI or tumor size were reported as prognostic factors in some studies $(3,4,6-9)$. Although the prognostic factors of NSCLC patients with CWI were not analyzed in the present study, the tumor size was indicated to be a risk factor of CWI. If a large tumor invades the chest wall at an early point, surgery should be performed as soon as possible before invasion to the 
Table 1 Patient characteristics

\begin{tabular}{|c|c|c|c|}
\hline Characteristics & \multicolumn{2}{|c|}{ Chest wall invasion } & $P$ value \\
\hline Gender (male/female) & $12 / 1$ & $110 / 34$ & 0.19 \\
\hline Age (median, range) & 65 [45-82] & 68 [38-89] & $0.04^{\star}$ \\
\hline Smoking index (median, range) & $900[360-2,150]$ & $822[0-3,660]$ & 0.40 \\
\hline $\mathrm{CT}_{\max }$ (median, range) & $63[27-151]$ & $40[13-150]$ & $<0.01^{*}$ \\
\hline$P_{\max }($ median, range) & $75[19-131]$ & 29 [3-244] & $<0.01^{*}$ \\
\hline SUV $_{\max }($ median, range) & 18.8 [8.39-28.46] & $9.4[0.89-37.9]$ & $<0.01^{*}$ \\
\hline Histology (Ad/Sq/others) & $7 / 4 / 2$ & $73 / 53 / 18$ & 0.89 \\
\hline cStage (IA/IB/IIA/IIB/IIIA) & $1 / 1 / 2 / 4 / 5$ & $33 / 28 / 22 / 27 / 34$ & 0.79 \\
\hline Ly $(0 / 1)$ & $7 / 6$ & $48 / 96$ & 0.13 \\
\hline$V(0 / 1)$ & $1 / 12$ & $35 / 108$ & 0.36 \\
\hline WBC (median, range) & $7,250[3,350-10,360]$ & $6,380[2,980-12,150]$ & 0.06 \\
\hline Plt (median, range) & $30.1[16-63.4]$ & $24.8[12-54.8]$ & 0.08 \\
\hline NLR (median, range) & $2.94[0.88-12.48]$ & $2.39[0.53-9.23]$ & 0.06 \\
\hline LDH (median, range) & 238 [177-285] & $193[133-448]$ & $<0.01^{*}$ \\
\hline CRP (median, range) & $0.6[0.09-15.79]$ & 0.19 [0.03-45] & $0.01^{*}$ \\
\hline
\end{tabular}

*, statistical significance. CEA, carcinoembryonic antigen; $\mathrm{CT}_{\max }$, maximum tumor diameter on computed tomography; $\mathrm{P}_{\max }$, tumor diameter adjacent to visceral pleura; SUV $\max$, maximum standardized uptake value; c, clinical; Ad, adenocarcinoma; Sq, squamous cell carcinoma; Patho ${ }_{\max }$, tumor diameter on pathological exam; G, grade of differentiation; c, clinical; Ly, Iymphatic invasion; V, vascular invasion; WBC, white blood cell; PIt, platelet; NLR, neutrophil-to-lymphocyte ratio; LDH, lactate dehydrogenase; CRP, C-reactive protein.

chest wall. Furthermore, the completeness of resection for NSCLC patients with CWI might be maintained before deep CWI occurs.

Because CWI (T3) with ipsilateral mediastinal lymph node metastasis (N2) is categorized as IIIB stage in the TNM staging system ( $8^{\text {th }}$ edition) $(10)$, the presence of CWI might determine the surgical indication in some cases. Therefore, it is important to clarify the risk factors of CWI for NSCLC patients. In the present study, several risk factors for CWI were revealed. First, young patients with NSCLC tended to develop CWI more frequently than older patients in our study. Although the median age of NSCLC patients with CWI was mainly reported to be $60-64$ years in previous studies $(3,7,8,12,15-19)$, there was no significant difference in the age between the visceral pleural invasion group and the no-pleural invasion group in one study (13). Because whether or not age is a risk factor for CWI in NSCLC patients was not mentioned in previous reports $(3,7,8,12,15-19)$, age as a risk factor for CWI in NSCLC patients should be verified in the future.

Second, the diameter of tumors adjacent to the visceral pleura was a risk factor for CWI in NSCLC patients in the present study. Because some CT findings were considered to be signs of CWI [e.g., tumor size $>3 \mathrm{~cm}$ between the mass and the pleura; obtuse angle between the tumor and chest wall; pleural thickening (20-23)], the diameter of tumors adjacent to the visceral pleura might be a predictive risk factor for CWI.

Third, $\mathrm{SUV}_{\max }$ was a risk factor for CWI in NSCLC patients in the present study. Although the $\mathrm{SUV}_{\max }$ was not mentioned to be a risk factor of CWI in previous reports, it was reported to be associated with tumor aggressiveness 
Table 2 Relationship between chest wall invasion and clinicopathological variables of non-small cell lung cancer patients divided by a receiver operating characteristics curve analysis

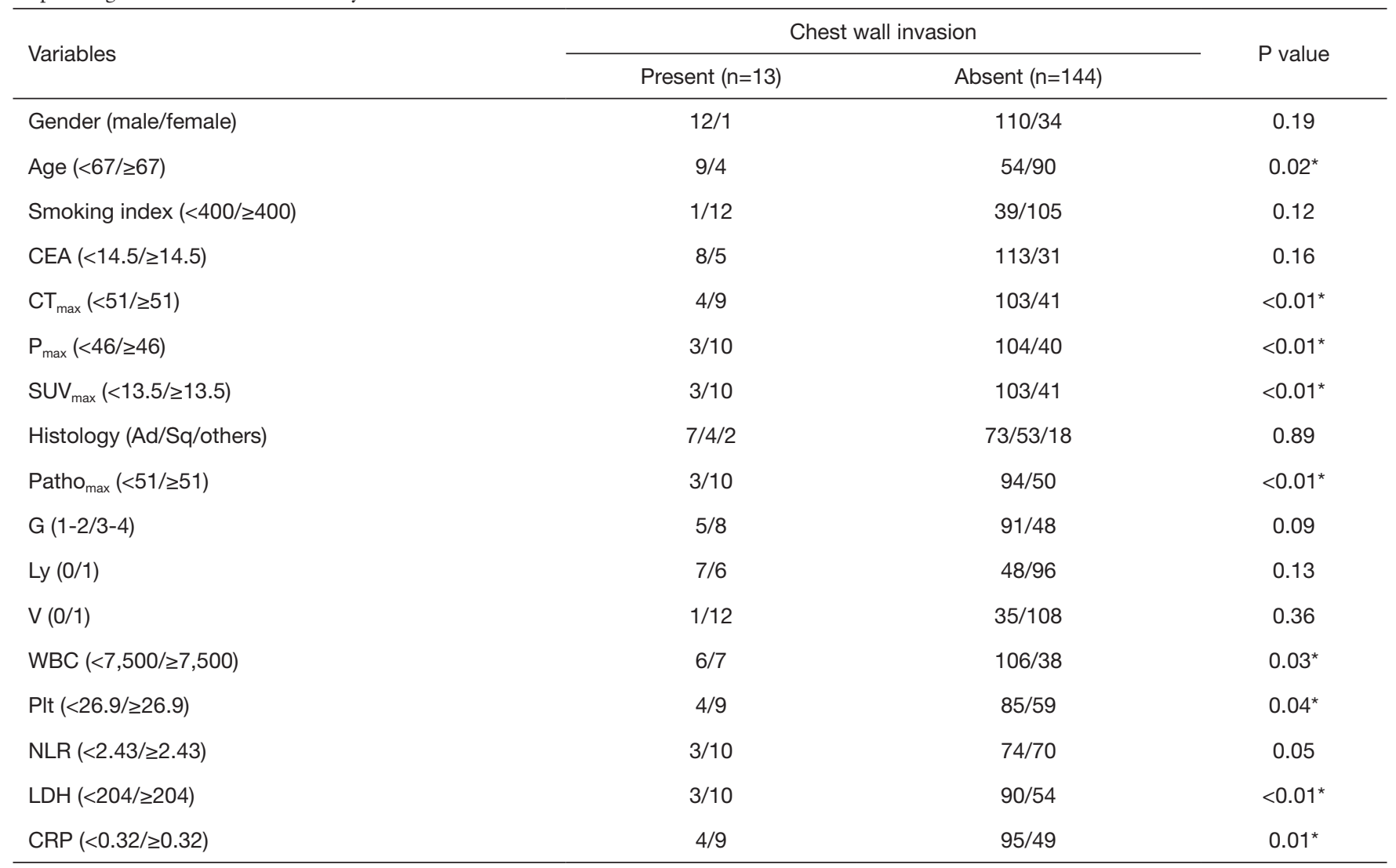

*, statistical significance. CEA, carcinoembryonic antigen; $\mathrm{CT}_{\max }$, maximum tumor diameter on computed tomography; $\mathrm{P}_{\max }$, tumor diameter adjacent to visceral pleura; SUV $\max$, maximum standardized uptake value; c, clinical; Ad, adenocarcinoma; Sq, squamous cell carcinoma; Patho ${ }_{\max }$, tumor diameter on pathological exam; G, grade of differentiation; Ly, lymphatic invasion; V, vascular invasion; WBC, white blood cell; PIt, platelet; NLR, neutrophil-to-lymphocyte ratio; LDH, lactate dehydrogenase; CRP, C-reactive protein.

Table 3 Logistic regression analysis

\begin{tabular}{lccc}
\hline Variables & OR & $95 \% \mathrm{Cl}$ & $\mathrm{P}$ value \\
\hline Age $(<67 / \geq 67)$ & 6.15 & $1.30-28.94$ & $0.02^{*}$ \\
$\mathrm{P}_{\max }(\geq 46 /<46)$ & 5.71 & $1.19-27.23$ & $0.02^{*}$ \\
$\operatorname{SUV}_{\max }(\geq 13.5 /<13.5)$ & 7.57 & $1.40-40.78$ & $0.01^{*}$ \\
$\operatorname{WBC}(\geq 7,500 /<7,500)$ & 0.80 & $0.15-4.25$ & 0.80 \\
$\operatorname{PIt}(\geq 26.9 /<26.9)$ & 3.54 & $0.66-18.93$ & 0.13 \\
$\operatorname{LDH}(\geq 204 /<204)$ & 10.54 & $1.90-58.23$ & $<0.01^{*}$ \\
$\operatorname{CRP}(\geq 0.32 /<0.32)$ & 0.81 & $0.13-5.02$ & 0.83 \\
\hline
\end{tabular}

*, statistical significance. OR, odds ratio; $\mathrm{Cl}$, confidence interval; $\mathrm{P}_{\max }$, tumor diameter adjacent to visceral pleura; $\mathrm{SUV} \mathrm{V}_{\max }$, maximum standardized uptake value; WBC, white blood cell; PIt, platelet; LDH, lactate dehydrogenase; CRP, C-reactive protein. 
(24-26). Furthermore, because the expression of Ki-67 and vascular endothelial growth factor in primary tumors was reported to be associated with $\mathrm{SUV}_{\text {max }}$ in NSCLC, this factor was suggested to have a close relationship with cancer proliferation, invasion, progression, and metastasis (27). Taken together, these findings suggest that $\mathrm{SUV}_{\text {max }}$ may be a risk factor for CWI in NSCLC patients.

Fourth, the LDH level was a risk factor for CWI in NSCLC patients in the present study. A high LDH level has been suggested to be associated with a poor prognosis in lung cancer (28-30). Furthermore, it was suggested that $\mathrm{LDH}-\mathrm{A}$, which is a cancer-specific isoform of $\mathrm{LDH}$, promotes invasion in gastric cancer (31). Because a high LDH level might be associated with tumor aggressiveness, the LDH level might be a risk factor for CWI in NSCLC patients. In NSCLC patients with these risk factors, surgery should be performed as soon as possible, before CWI can occur.

\section{Limitations}

Of note, this study is associated with several limitations, including the small sample size, retrospective nature, and single-institution setting.

In conclusions, four risk factors were suggested to be related to CWI due to NSCLC: the age, diameter of tumors adjacent to the visceral pleura, $\mathrm{SUV}_{\max }$, and $\mathrm{LDH}$ level. Surgery should therefore be performed as soon as possible when these risk factors are present, before CWI can occur.

\section{Acknowledgments}

Funding: None.

\section{Footnote}

Reporting Checklist: The authors have completed the STROBE reporting checklist. Available at http://dx.doi. org/10.21037/jtd-20-1722

Data Sharing Statement: Available at http://dx.doi. org/10.21037/jtd-20-1722

Conflicts of Interest: All authors have completed the ICMJE uniform disclosure form (available at http://dx.doi. org/10.21037/jtd-20-1722). The authors have no conflicts of interest to declare.
Ethical Statement: The authors are accountable for all aspects of the work in ensuring that questions related to the accuracy or integrity of any part of the work are appropriately investigated and resolved. The study was conducted in accordance with the Declaration of Helsinki (as revised in 2013). The institutional review boards of Kanazawa Medical University approved the protocol (the approval number: I392), and written informed consent was obtained from all patients.

Open Access Statement: This is an Open Access article distributed in accordance with the Creative Commons Attribution-NonCommercial-NoDerivs 4.0 International License (CC BY-NC-ND 4.0), which permits the noncommercial replication and distribution of the article with the strict proviso that no changes or edits are made and the original work is properly cited (including links to both the formal publication through the relevant DOI and the license). See: https://creativecommons.org/licenses/by-nc-nd/4.0/.

\section{References}

1. Pairolero PC. Extended resections for lung cancer. How far is too far? Eur J Cardiothorac Surg 1999;16:S48-S50.

2. Pearson FG. Non-small cell lung cancer. Role of surgery for stage I-III. Chest 1999;116:500S-503S.

3. Voltolini L, Rapicetta C, Luzzi L, et al. Lung cancer with chest wall involvement: predictive factors of long-term survival after surgical resection. Lung Cancer 2006;52:359-64.

4. Stoelben E, Ludwig C. Chest wall resection for lung cancer: indications and techniques. Eur J Cardiothorac Surg 2009;35:450-6.

5. Coleman FP. Primary carcinoma of the lung, with invasion of the ribs: pneumonectomy and simultaneous block resection of the chest wall. Ann Surg 1947;126:156-68.

6. Roviaro G, Varoli F, Grignani F, et al. Non-small cell lung cancer with chest wall invasion. Evolution of surgical treatment and prognosis in the last 3 decades. Chest 2003;123:1341-7.

7. Matsuoka H, Nishio W, Okada M, et al. Resection of chest wall invasion in patients with non-small cell lung cancer. Eur J Cardiothorac Surg 2004;26:1200-4.

8. Lee CY, Byun CS, Lee JG, et al. The prognostic factors of resected non-small cell lung cancer with chest wall invasion. World J Surg Oncol 2012;10:9.

9. Filosso PL, Sandri A, Guerrera F, et al. Primary lung tumors invading the chest wall. J Thorac Dis 2016;8:S855-S862. 
10. Rami-Porta R. Bolejack V, Crowley J, et al. The IASLC lung cancer staging project. Proposals for the revisions of the $\mathrm{T}$ descriptors in the forthcoming eighth edition of the TNM classification for lung cancer. J Thorac Oncol 2015;10:990-1003.

11. Kanou T, Shintani Y, Ikeda N, et al. Prognosis of pT3N0M0 patients with resectable non-small cell lung cancer invading the chest wall. JJLC 2009;49:8-11.

12. Bai JH, Hsieh MS, Liao HC, et al. Prediction of pleural invasion using different imaging tools in non-small cell lung cancer. Ann Transl Med 2019;7:33.

13. Hsu JS, Han IT, Tsai TH, et al. Pleural tags on CT scans to predict visceral pleural invasion of non-small cell lung cancer that dose not about the pleura. Radiology 2016;279:590-6.

14. Akata S, Kajiwara N, Park J, et al. Evaluation of chest wall invasion by lung cancer using respiratory bynamic MRI. J Med Imaging Radiat Oncol 2008;52:36-39.

15. Tahiri M, Khereba M, Thiffault V, et al. Preoperative assessment of chest wall invasion in non-small cell lung cancer using surgeon-performed ultrasound. Ann Thorac Surg 2014;98:984-9.

16. Ratto GB, Piacenza G, Frola C, et al. Chest wall involvement by lung cancer: computed tomography detection and results of operation. Ann Thorac Surg 1991;51:182-8.

17. Doddoli C, D'Journo B, Pimpec-Barthes FL, et al. Lung cancer invading the chest wall: a plea for en-bloc resection but the need for new treatment strategies. Ann Thorac Surg 2005;80:2032-40.

18. Magdeleinat P, Alifano M, Benbrahem C, et al. Surgical treatment of lung cancer invading the chest wall: results and prognostic factors. Ann Thorac Surg 2001;71:1094-9.

19. Santos HTA, Lopes AJ, Higa C, et al. Lung cancer with chest wall invasion: retrospective analysis comparing enbloc resection and 'resection in bird cage'. J Cardiothorac Surg 2014;9:57.

20. Ebara K, Takashima S, Jiang B, et al. Pleural invasion by peripheral lung cancer: prediction with three-dimentional CT. Acad Radiol 2015;22:310-9.

21. Glazer HS, Duncan-Meyer J, Aronberg DJ, et al. Pleural and chest wall invasion in bronchogenic carcinoma: CT evaluation. Radiology 1985;157:191-4.

22. Imai K, Minamiya $\mathrm{Y}$, Ishiyama $\mathrm{K}$, et al. Use of CT to evaluate pleural invasion in non-small cell lung cancer: measurement of the ratio of the interface between tumor and neighboring structures to maximum tumor diameter. Radiology 2013;267:619-26.

23. Verschakelen JA, Bogaert J, De Wever W. Computed tomography in staging for lung cancer. Eur Respir J Suppl 2002;35:40s-48s.

24. Paesmans M, Berghmans T, Dusart M, et al. Primary tumor standardized uptake value measured on fluorodeoxyglucose positron emission tomography is of prognostic value for survival in non-small cell lung cancer: update of a systematic review and meta-analysis by the European Lung Cancer Working Party for the International Association for the Study of Lung Cancer Staging Project. J Thorac Oncol 2010;5:612-9.

25. Chang AJ, Dehdashti F, Bradley JD. The role of positron emission tomography for non-small cell lung cancer. Pract Radiat Oncol 2011;1:282-8.

26. Kosaka T, Yamaki E, Tanaka S, et al. Preoperative 18F-fluorodeoxyglucose positron emission tomography can predict the tumor malignancy of small peripheral lung cancer. Ann Thorac Cardiovasc Surg 2014;20:968-73.

27. Takenaka T, Yano T, Ito K, et al. Biological significance of the maximum standardized uptake values on positron emission tomography in non-small cell lung cancer. J Surg Oncol 2009;100:688-92.

28. Zheng X, Wang K, Xu L, et al. The effect of serum lactate dehydrogenase levels on lung cancer prognosis: a metaanalysis. Int J Clin Exp Med 2017;10:14179-86.

29. Deng T, Zhang J, Meng Y, et al. High pretreatment lactate dehydrogenase concentration predicts worse overall survival in patients with lung cancer. Medicine 2018;97:38.

30. Zhang Z, Li Y, Yan X, et al. Pretreatment lactate dehydrogenase may predict outcome of advanced non small-cell lung cancer patients treated with immune checkpoint inhibitors: a meta-analysis. Cancer Med 2019;8:1467-73.

31. Liu X, Yang Z, Chen Z, et al. Effects of the suppression of lactate dehydrogenase A on the growth and invasion of human gastric cancer cells. Oncol Rep 2015;33:157-62.

Cite this article as: Motono N, Iwai S, Yamagata A, Iijima Y, Usuda K, Yamada S, Uramoto H. Risk factors of chest wall invasion in non-small cell lung cancer. J Thorac Dis 2021;13(2):824-830. doi: 10.21037/jtd-20-1722 